\title{
The crystal structure of alanine racemase from Streptococcus pneumoniae, a target for structure-based drug design
}

\author{
Hookang Im, Miriam L Sharpe ${ }^{2}$, Ulrich Strych ${ }^{3}$, Milya Davlieva ${ }^{4}$ and Kurt L Krause $2^{2^{*}}$
}

\begin{abstract}
Background: Streptococcus pneumoniae is a globally important pathogen. The Gram-positive diplococcus is a leading cause of pneumonia, otitis media, bacteremia, and meningitis, and antibiotic resistant strains have become increasingly common over recent years. Alanine racemase is a ubiquitous enzyme among bacteria and provides the essential cell wall precursor, D-alanine. Since it is absent in humans, this enzyme is an attractive target for the development of drugs against S. pneumoniae and other bacterial pathogens.

Results: Here we report the crystal structure of alanine racemase from S. pneumoniae (Alrsp). Crystals diffracted to a resolution of $2.0 \AA$ and belong to the space group P 3,21 with the unit cell parameters $a=b=119.97 \AA, c=$ $118.10 \AA, \alpha=\beta=90^{\circ}$ and $\gamma=120^{\circ}$. Structural comparisons show that Alrsp shares both an overall fold and key active site residues with other bacterial alanine racemases. The active site cavity is similar to other Gram positive alanine racemases, featuring a restricted but conserved entryway.

Conclusions: We have solved the structure of Alrsp, an essential step towards the development of an accurate pharmacophore model of the enzyme, and an important contribution towards our on-going alanine racemase structure-based drug design project. We have identified three regions on the enzyme that could be targeted for inhibitor design, the active site, the dimer interface, and the active site entryway.
\end{abstract}

\section{Background}

Despite great advances in the development of antibiotics, the most common cause of community-acquired pneumonia, Streptococcus pneumoniae, is still a globally important pathogen, especially in children and the elderly [1]. This Gram-positive diplococcus is a leading cause not only of pneumonia, but also otitis media, bacteremia, and meningitis [2,3]. In children, S. pneumoniae is estimated to cause more than one-third of the 2 million deaths due to acute respiratory infections $[4,5]$. In the elderly, S. pneumoniae is the most common cause of fatal community-acquired pneumonia [6,7]. In adults from industrialized countries, pneumococcal pneumonia accounts for at least $30 \%$ of all cases of communityacquired pneumonia admitted to hospital, with a fatality rate of $11 \%$ to $44 \%$ [4]. In addition, co-infection of influenza patients with S. pneumoniae is known to

\footnotetext{
* Correspondence: kurt.krause@otago.ac.nz

2Department of Biochemistry, University of Otago, Dunedin, New Zealand Full list of author information is available at the end of the article
}

exacerbate their clinical outcome [4]: for example, $50 \%$ or more of the flu-associated mortality in the 1918-1919 Spanish Flu epidemic is believed to have resulted from pneumococcal superinfections [8,9], and S. pneumoniae co-infection has been specifically correlated with the severity of the recent H1N1 pandemic influenza [10]. The rate of antibiotic resistance in S. pneumoniae has escalated dramatically since penicillin-resistant strains were first detected in the 1970s [11-15]. About 40\% of pneumococcal isolates displayed multidrug-resistant phenotypes (resistance to three or more antibiotics) across 38 countries in 2004 [16,17]. To meet the challenge of increasing pneumococcal drug resistance it will be important to isolate new therapeutic compounds effective against S. pneumoniae through the identification of new target enzymes and the development of effective inhibitors to these targets.

The bacterial enzyme alanine racemase (Alr; E.C. 5.1.1.1) uses a covalently-bound pyridoxal 5"-phosphate (PLP) cofactor to catalyze the racemization of L-alanine
C Biomed Central

(c) 2011 Im et al; licensee BioMed Central Ltd. This is an Open Access article distributed under the terms of the Creative Commons Attribution License (http://creativecommons.org/licenses/by/2.0), which permits unrestricted use, distribution, and reproduction in any medium, provided the original work is properly cited. 
and D-alanine, the latter being an essential component of the peptidoglycan layer in bacterial cell walls [18]. Microbiological evidence has consistently shown this enzyme to be essential in bacteria [19]. One apparent exception was found for the Mycobacterium smegmatis enzyme, which was able tolerate an insertion in its alanine racemase gene [20]. But this exception was disproved with the report of an alanine racemase deletion mutant in $M$. smegmatis that did not grow without Dalanine supplementation [19]. S. pneumoniae, unlike Escherichia coli or Pseudomonas aeruginosa, contains only one gene that codes for alanine racemase [21]. The lack of alanine racemase function in eukaryotes [22] makes this enzyme an attractive target for antimicrobial drug development. Structural studies are crucial to structure-based drug design [23-25], and solving the crystal structure of alanine racemase from $S$. pneumoniae $\left(\mathrm{Alr}_{\mathrm{SP}}\right)$ is a crucial step towards designing inhibitors of this enzyme.

To date, crystal structures of alanine racemase enzymes from seven different bacteria have been published: Geobacillus stearothermophilus $\left(\mathrm{Alr}_{\mathrm{GS}}\right)$ [26-31], P. aeruginosa (DadX $\mathrm{PA}_{\mathrm{PA}}$ ) [32], Streptomyces lavendulae $\left(\mathrm{Alr}_{\mathrm{SL}}\right)$ [33], Mycobacterium tuberculosis $\left(\mathrm{Alr}_{\mathrm{MT}}\right)$ [34], Bacillus anthracis $\left(\mathrm{Alr}_{\mathrm{BA}}\right)$ [35,36], E. coli $\left(\mathrm{Alr}_{\mathrm{EC}}\right)$ [37], and Enterococcus faecalis $\left(\mathrm{Alr}_{\mathrm{EF}}\right)$ [38]. Structures of this enzyme from a further six microorganisms have been deposited in the PDB: Bartonella henselae (PDB ID 3KW3), Oenococcus oeni (3HUR and 3CO8), Pseudomonas fluorescens (2ODO), Actinobacillus succinogenes (3C3K), Corynebacterium glutamicum (2DY3), and Staphylococcus aureus (3OO2). In all of these structures, Alr is a homodimeric enzyme formed by a head-to-tail association of two monomers. Each monomer is composed of an $N$-terminal $\alpha / \beta$ barrel and an extended $\beta$ strand domain at the $\mathrm{C}$-terminus. The active site in each monomer is located in the centre of the $\alpha / \beta$ barrel and contains a pyridoxal phosphate (PLP) co-factor covalently connected to a lysine residue by an internal aldimine bond. The catalytic mechanism is thought to involve two bases, the same lysine, and a tyrosine contributed by the opposite monomer $[30,39,40]$. The entryway to the active site and the PLP binding site consists of residues from loops in the $\alpha / \beta$ barrel domain of one monomer and residues from the $\mathrm{C}$-terminal domain of the other monomer, and is roughly conical, with its base oriented toward the outside of the enzyme [34]. Structures of alanine racemase in complex with substrate analogs [27,28,30-32] and site-directed mutagenesis of the enzyme $[31,40,41]$ have elucidated the reaction mechanism of the enzyme and verified the key roles of active site residues. Structures of alanine racemase complexed with alanine phosphonate and D-cycloserine (DCS) show that these inhibitors covalently bind to the
PLP cofactor, which explains their ability to inhibit eukaryotic PLP-containing enzymes in a non-specific manner [27,30,37,38].

Determining the structure of alanine racemase from a range of bacterial species is an important step towards its full characterization in anticipation of inhibitor design. Here, we report the structure of $\mathrm{Alr}_{\mathrm{SP}}$, and compare it with other published alanine racemase structures. This crystal structure will contribute useful information towards our structure-based drug design research aimed at the identification and development of alanine racemase inhibitors.

\section{Results and discussion}

\section{Structure determination and refinement}

Crystals of $\mathrm{Alr}_{\mathrm{SP}}$ suitable for X-ray diffraction were grown as described previously [21]. Crystals diffracted to a resolution of $2.0 \AA$ and belong to the space group P3 21 with the unit cell parameters $\mathrm{a}=\mathrm{b}=119.97 \AA$, $\mathrm{c}=118.10 \AA, \alpha=\beta=90^{\circ}$ and $\gamma=120^{\circ}$. The structure of $\mathrm{Alr}_{\mathrm{SP}}$ was solved by molecular replacement using CNS [42] and Alr $_{\text {GS }}$ (PDB ID 1SFT) [29] without the PLP cofactor as a search model. Refinement was carried out initially with CNS, then completed with TLS refinement [43] in Refmac5 [44]. After structure solution and refinement, the final model of $\mathrm{Alr}_{\mathrm{SP}}$, validated using PROCHECK [45] has $92.7 \%$ of residues in the most favored regions of the Ramachandran plot, $6.9 \%$ of residues in the additionally allowed regions and $0.3 \%$ of residues in the generously allowed regions. The structure has root-mean-square (r.m.s.) deviations from ideality for bond lengths of $0.015 \AA$ and for angles of $1.45^{\circ}$. Further data collection and refinement statistics are presented in Table 1 .

\section{Overall structure of Alr $r_{\mathrm{SP}}$}

$\mathrm{Alr}_{\mathrm{SP}}$ forms a homodimer in which the two monomers form a head-to-tail association, typical of that seen in other alanine racemases. Each monomer has an eightstranded $\alpha / \beta$ barrel domain (residues 1-238) and an extended $\beta$-strand domain (residues 239-367) (Figure $1 \mathrm{~A})$. The $\alpha / \beta$ barrel of one monomer is in contact with the $\beta$-strand domain of the other monomer (Figure $1 \mathrm{~B}$ ). Although the two monomers have very similar folds, they are crystallographically distinct in this crystal form (Table 1), and noncrystallographic symmetry was not used in refinement. The r.m.s. difference between the $\mathrm{C} \alpha$ atoms of the two monomers after superposition is $0.38 \AA$, and the average $\mathrm{B}$-factors of monomers $\mathrm{A}$ and $\mathrm{B}$ are 38.4 and $46.9 \AA^{2}$, respectively. As with other alanine racemases, the $\mathrm{Alr}_{\mathrm{SP}}$ homodimer contains two active sites, each composed of residues from the $\alpha / \beta$ barrel of one monomer and residues from the $\beta$-strand domain of the other. The pyridoxal phosphate (PLP) cofactor is 
Table 1 Data collection and structure refinement statistics

\begin{tabular}{|c|c|}
\hline Data collection & \\
\hline Unit cell parameters & $\begin{array}{l}\mathrm{a}=119.97 \AA, \mathrm{b}=119.97 \AA \\
\mathrm{c}=118.10 \AA\end{array}$ \\
\hline & $\alpha=90^{\circ}, \beta=90^{\circ}, \gamma=120^{\circ}$ \\
\hline Space group & $P 3,21$ \\
\hline$\lambda(\AA)$ & 1.5418 \\
\hline Mosaicity & 0.48 \\
\hline Observations & 475265 \\
\hline Unique reflections & 66748 \\
\hline R-merge $^{a}(\%)$ & $8.3(68.2)$ \\
\hline Completeness (\%) & $99.6(95.4)$ \\
\hline$<\mid / \sigma>$ & $21.3(1.7)$ \\
\hline Refinement statistics & \\
\hline Resolution $(\AA)$ & $23.03-2.00(2.05-2.00)$ \\
\hline Reflections & $63336(4412)$ \\
\hline Total atoms & 6161 \\
\hline R-factor ${ }^{\mathrm{b}}(\%)$ & $16.8(32.2)$ \\
\hline$R_{\text {free }}(\%)$ & $20.0(35.5)$ \\
\hline Average B-factors $\left(\AA^{2}\right)$ & \\
\hline Wilson B-factor & 33.2 \\
\hline All atoms & 42.7 \\
\hline Main chain atoms & 41.8 \\
\hline Side chain atoms and waters & 43.6 \\
\hline Waters & 44.5 \\
\hline R.m.s. deviations & \\
\hline Bond lengths $(\AA)$ & 0.015 \\
\hline Bond angles (deg) & 1.45 \\
\hline No. of residues & $734,100 \%$ \\
\hline No. of protein atoms & 5615 \\
\hline No. of PLP atoms & 30 \\
\hline $\begin{array}{l}\text { No. of benzoic acid atoms No. of } \\
\text { water molecules }\end{array}$ & 9507 \\
\hline
\end{tabular}

Residues in the Ramachandran plot

Most favored regions

$588,92.7 \%$

Additionally allowed regions

$44,6.9 \%$

Generously allowed regions

Disallowed regions

$2,0.3 \%$

$0,0 \%$

\footnotetext{
${ }^{a}$ R-merge $=\left.\Sigma||_{\text {obs }}{ }^{-}{ }_{\text {avg }}|/ \Sigma|\right|_{\text {avg }} \mid$

${ }^{\mathrm{b}} \mathrm{R}$-factor $=\Sigma\left|F_{\text {obs }}-F_{\text {calc }}\right| \Sigma\left|F_{\text {obs }}\right|$

Values in parenthesis are for the highest resolution shell.
}

connected to Lys40 through an internal aldimine bond and resides inside the $\alpha / \beta$ barrel domain.

As an incidental finding, the Alr $_{\mathrm{SP}}$ structure contained additional electron density within the A monomer, at the end of helix 1 in the $\mathrm{N}$-terminal $\alpha / \beta$ barrel domain. This planar density resembled a carboxylated aromatic ring, therefore a benzoic acid molecule, which fitted and refined well, was modeled into this region, even though the compound was not added to purification or crystallization conditions (topology and parameters obtained from the Hetero-compound Information Centre-Uppsala, HIC-UP [46]). It is situated some distance away from both the active site entryway and the dimer interface.

\section{Structural and biochemical comparison with closely related alanine racemases}

As noted in our previous publication [21], Alr $\mathrm{AP}_{\mathrm{SP}}$ displays a high level of sequence similarity with other alanine racemases. The structure-based sequence alignment in Figure 2 demonstrates this similarity with alanine racemases from other Gram-positive bacteria: $\mathrm{Alr}_{\mathrm{EF}}$ (which has $52 \%$ sequence identity with $\mathrm{Alr}_{\mathrm{SP}}$ ), $\mathrm{Alr}_{\mathrm{GS}}$ (46\% identity), $\mathrm{Alr}_{\mathrm{BA}}$ (38\% identity), and $\mathrm{Alr}_{\mathrm{SL}}$ (36\% identity). Regions absolutely conserved across all of these enzymes include the characteristic PLP binding site motif near the N-terminus (AVVKANAYGHG), the two catalytic amino acid residues of the active center (Lys40, Tyr263'; throughout this paper, primed numbers denote residues from the second monomer) and the eight residues making up the entryway to the active site (inner layer: Tyr263', Tyr352, Tyr282', and Ala169; middle layer: Arg307', Ile350, Arg288', and Asp170).

Superposition of the $\mathrm{C} \alpha$ atoms of monomer A from $\mathrm{Alr}_{\mathrm{SP}}$ with equivalent alanine racemase domains from other Gram-positive bacteria confirms the overall topological similarity between these structures (Figure 3A). There are minor conformational differences between these alanine racemases at the $\mathrm{N}$ - and $\mathrm{C}$-termini and some loops in the $\alpha / \beta$-barrel domain. $\mathrm{Alr}_{\mathrm{SP}}$ is similar in length to $\mathrm{Alr}_{\mathrm{SL}}$ and $\mathrm{Alr}_{\mathrm{EF}}$; whereas $\mathrm{Alr}_{\mathrm{GS}}$ and $\mathrm{Alr}_{\mathrm{BA}}$ have 15 to 19 extra residues at the $\mathrm{C}$-terminus that form an extra $\beta$-strand and helix/turn which contact the N-termini and the closest two helices of the $\alpha / \beta$-barrel of each structure, and do not form part of the active site. The significance of these extra residues or lack thereof is unknown; future mutagenesis or domain-swap experiments may help to uncover their function.

Within each alanine racemase, the $\mathrm{C}$ - and $\mathrm{N}$-terminal domains of each monomer are structurally distinct, and the hinge angle varies between the different enzymes $[32,36]$, thereby preventing the optimal superposition of whole monomers. Overlaying the $\mathrm{C} \alpha$ atoms of $\mathrm{Alr}_{\mathrm{SP}}$ and alanine racemase structures from other Gram-positive bacteria results in average r.m.s. differences of 1.16-1.57 $\AA$ (Table 2), but when the $\mathrm{N}$-terminal and C-terminal domains from $\mathrm{Alr}_{\mathrm{SP}}$ are superimposed separately, the Cterminal domain is shown to be more conserved (average r.m.s. differences of 0.49-1.24 $\AA$ ), than the N-terminal domain (r.m.s. of 1.30-1.92 $\AA$ ). Domain boundaries and residues used in these superpositions are listed in Table 3. The subset of residues found in the active site of $\mathrm{Alr}_{\mathrm{SP}}$ superpose very well with the equivalent residues of the other structures (r.m.s. of 0.36-0.67 $\AA$ ). C-termini 

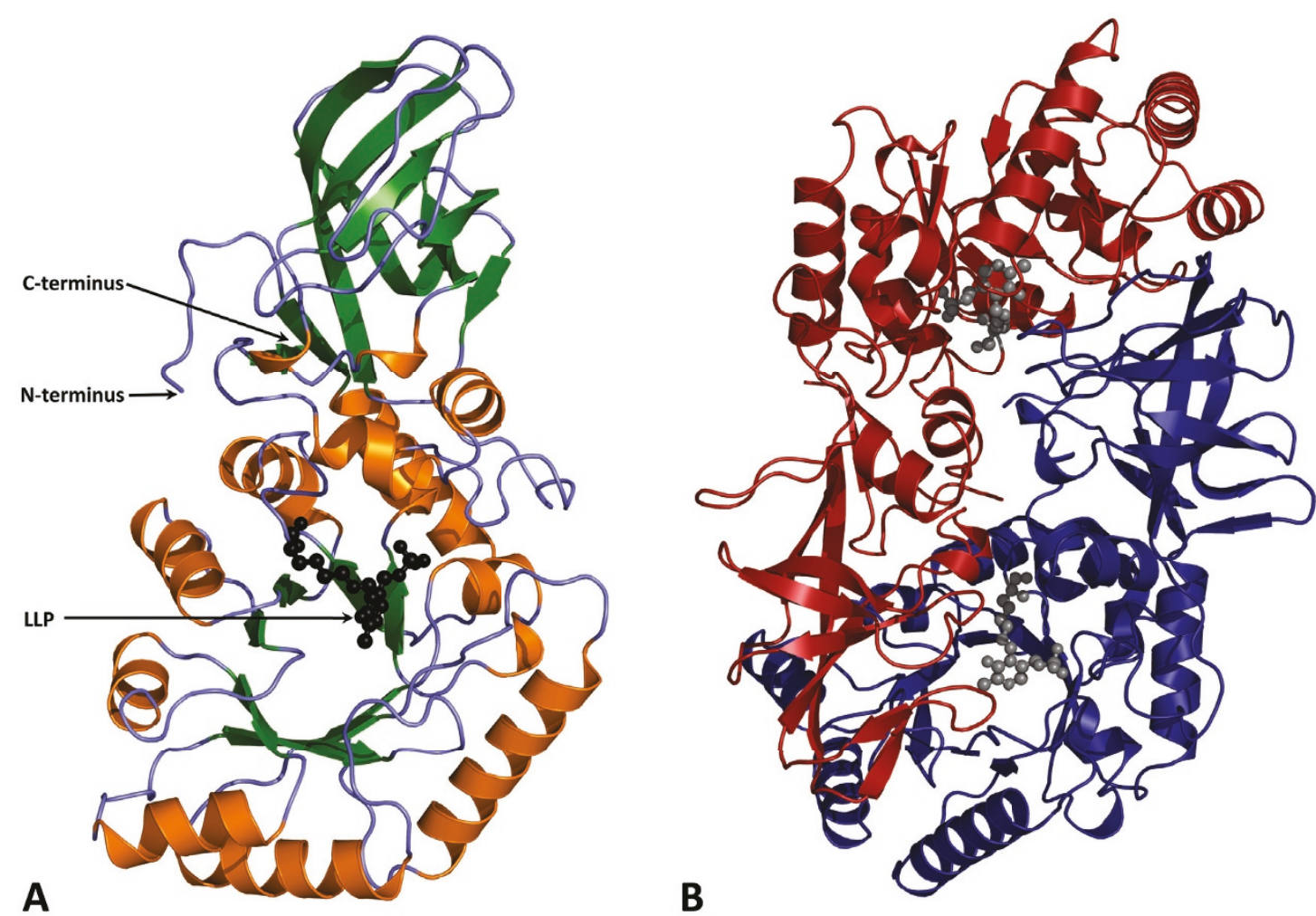

Figure 1 Structure of alanine racemase from S. pneumoniae. (A) Ribbon diagram of the alanine racemase monomer with $\beta$-sheets colored green and $\alpha$-helices colored gold. (B) Ribbon diagram of the alanine racemase dimer where one monomer is colored blue and the opposite monomer red. The N'-pyridoxyl-lysine-5'-monophosphate or LLP residue (PLP cofactor covalently bound to lysine; black or grey spheres) resides in the $\alpha / \beta$ barrel domain of the active site. The active site is composed of residues from the $\alpha / \beta$ barrel domain of one monomer and residues from the $\beta$-strand domain of the other monomer.

and active site residues superpose particularly well between $\operatorname{Alr}_{\mathrm{SP}}$ and $\mathrm{Alr}_{\mathrm{GS}}$, and also between $\mathrm{Alr}_{\mathrm{BA}}$ and $\mathrm{Alr}_{\mathrm{EF}}$. This structural similarity explains why $\mathrm{Alr}_{\mathrm{GS}}$ was such a successful molecular replacement model. Variability in the N-terminal domain is further illustrated by superposition of the $\mathrm{N}$-terminal domains of $\mathrm{Alr}_{\mathrm{SP}}$ and its closest available homolog, $\mathrm{Alr}_{\mathrm{EF}}$, which reveals significant deviations in $C \alpha$ positions $(\geq 1.8 \AA)$ for five regions: residues $27-29$, residues $53-58$, residues 109 122, residues 150-156, and residues 192-196 (Figure 3B). The sequence in these regions is not highly conserved and they lie far from the active site. Superposition of the $\mathrm{C}$-terminal domains from these structures shows no region with $\mathrm{C} \alpha$ differences greater than $1.7 \AA$. Overall, alanine racemase structures seem to tolerate significant alterations in the backbone of the $\alpha / \beta$-barrel and $\beta$ domain and still retain almost identical active site residue locations.

The kinetic properties for $\mathrm{Alr}_{\mathrm{SP}}$ [21] are within the range of those previously observed for other bacterial alanine racemases (Table 4). The $\mathrm{K}_{\mathrm{M}}$ for L-alanine is 1.9 $\mathrm{mM}$ and $\mathrm{V}_{\max }$ for the racemization of $\mathrm{L}$ - to $\mathrm{D}$-alanine is $84.8 \mathrm{U} / \mathrm{mg}$, where one unit is defined as the amount of enzyme that catalyzes racemization of $1 \mu \mathrm{mol}$ of substrate per minute. In the other direction, the $\mathrm{K}_{\mathrm{M}}$ for $\mathrm{D}$ alanine is $2.1 \mathrm{mM}$ and $\mathrm{V}_{\max }$ for the racemization of Lto $\mathrm{D}$-alanine is $87.0 \mathrm{U} / \mathrm{mg}$. However, the $\mathrm{V}_{\max }$ for the $S$. pneumoniae enzyme is more than one order of magnitude lower than that reported for the G. stearothermophilus and E. faecalis enzymes, even though the active site of $\mathrm{Alr}_{\mathrm{SP}}$ has high sequence and structural similarities with these alanine racemases. Differences of up to three orders of magnitude have been reported in this family despite very similar active sites.

\section{Hinge angle}

The hinge angle of the A monomer of $\mathrm{Alr}_{\mathrm{SP}}$, formed by the $\mathrm{C} \alpha$ atoms of residues 99,38 and 270 in the N-terminal $\alpha / \beta$ barrel domain and the $C$-terminal $\beta$-strand domain, is $132.3^{\circ}$. This is well within the range of hinge angles found between corresponding residues in the other Gram-positive alanine racemase structures $\left(127.6^{\circ}\right.$ for $\mathrm{Alr}_{\mathrm{BA}}, 129.4^{\circ}$ for $\mathrm{Alr}_{\mathrm{GS}}, 131.6^{\circ}$ for $\mathrm{Alr}_{\mathrm{EF}}$, and $138.2^{\circ}$ for $A \mathrm{Al}_{\mathrm{SL}}$ ). The difference in the degree of tilt between the C-terminal domains for the five structures can be seen in Figure 3A. Hydrogen bonding between the C- 


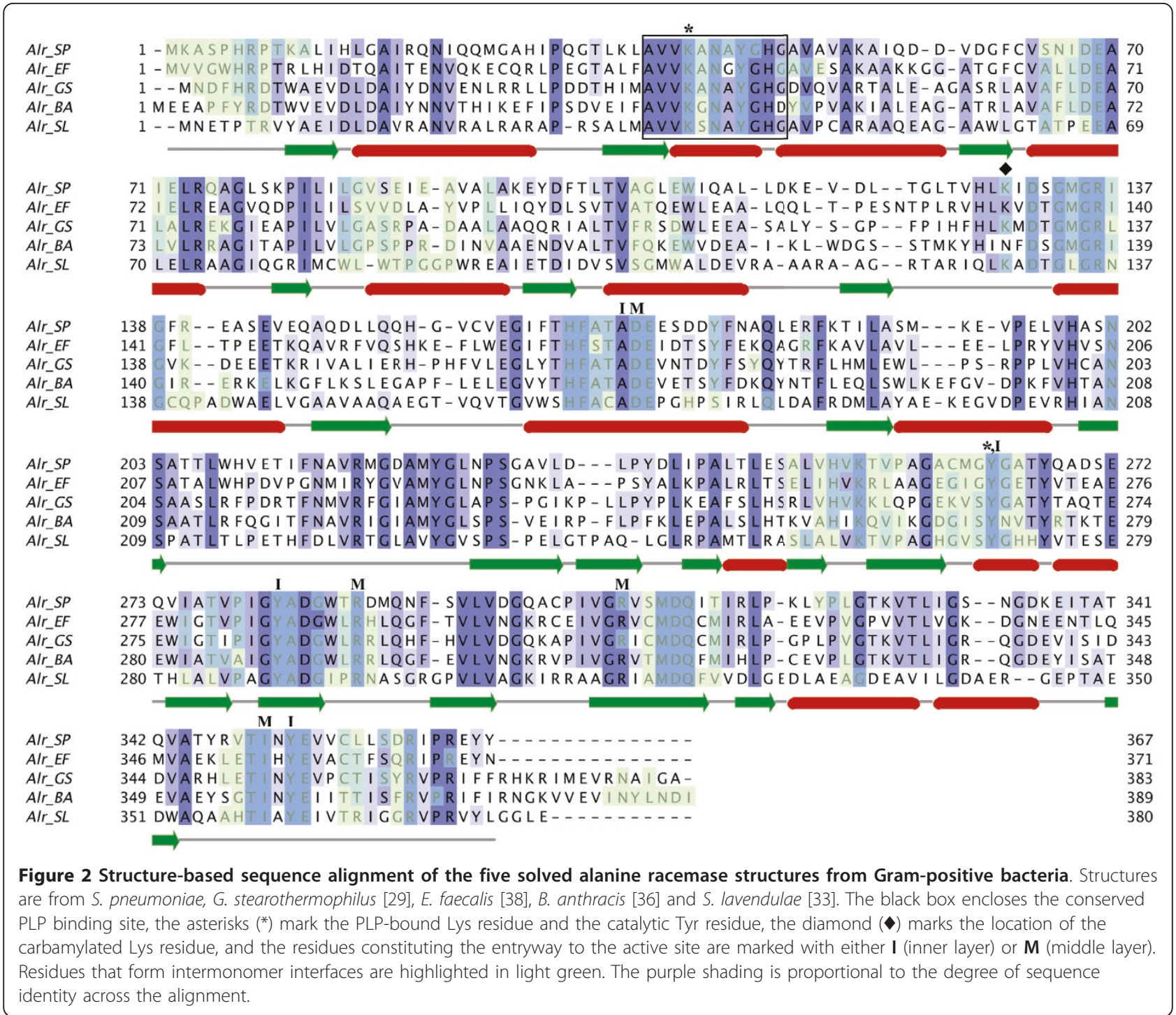

and N-terminal tails of opposite monomers was proposed by LeMagueres et al. to account for the distinct domain orientations of $\mathrm{Alr}_{\mathrm{MT}}$ and $\mathrm{DadX}_{\mathrm{PA}}$ [34]. Alanine racemase structures with extra residues at the $\mathrm{N}$ - and C-terminal tails, such as $\mathrm{Alr}_{\mathrm{GS}}$ and $\mathrm{Alr}_{\mathrm{BA}}$, often form these hydrogen bonds, which are associated with smaller hinge angles $\left(127.6^{\circ}\right.$ for $\mathrm{Alr}_{\mathrm{BA}}, 129.4^{\circ}$ for $\mathrm{Alr}_{\mathrm{GS}}$ )[36].

Although the hinge angle clearly varies from species to species for this enzyme, the active sites superpose very well. Further, there is no correlation between hinge angle and Vmax (data not shown). On the other hand, there is some correlation between alanine racemase activity and bacterial doubling time. For example, the enzyme from the slow growing $M$. tuberculosis is very slow compared to the same enzyme from the rapid growing $M$. smegmatis species. It has previously been noted that only the dimeric form of the enzyme is active
[47] and that many of the alanine racemase enzymes with the strongest monomer-dimer association have been found to be the most active [48]. A recent report has appeared looking at how enzyme activity in different alanine racemases relates to self-association affinity and this report confirms this assertion [49].

\section{Active site}

The geometry and identities of the active site residues of $\mathrm{Alr}_{\mathrm{SP}}$ (Figure 4A) are very similar to that of other alanine racemases (Figure 4B). The main components of the $\mathrm{Alr}_{\mathrm{SP}}$ active site include the PLP cofactor covalently bound to Lys40 (forming an N'-pyridoxyl-lysine-5'-monophosphate or LLP residue), the catalytic base residue Tyr263' which lies at the beginning of helix 11 in the $\beta$-strand domain (contributed by the opposite monomer to that providing Lys40), and a hydrogen-bonded network 

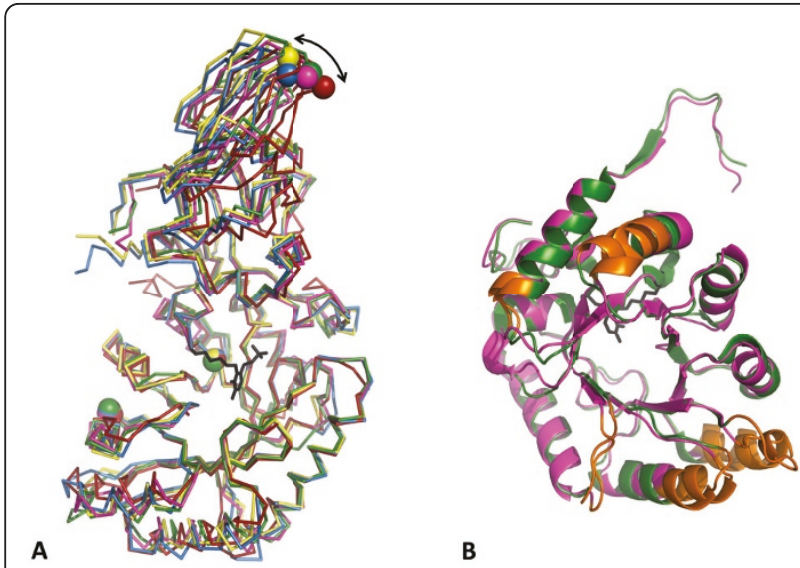

Figure 3 Superposition of alanine racemase monomers from Gram-positive bacteria. (A) $\mathrm{C} \alpha$ atom traces of alanine racemases from G. stearothermophilus (yellow) [29], E. faecalis (green) [38], B. anthracis (blue) [36], S. lavendulae (red) [33], and S. pneumoniae (pink). The superposed $N$-terminal $\alpha / \beta$ barrel domains are oriented on the bottom of the picture and the $C$-terminal $\beta$-strand domains on the top. Spheres represent the three structurally equivalent residues used to measure the hinge angle in each structure. The double-headed arrow indicates the variation between hinge angles. The PLP-bound Lys residue from Alr ${ }_{\text {SP }}$ is shown in black. (B)

Superposed ribbon representations of the $\mathrm{N}$-terminal domains from E. faecalis (green) [38] and S. pneumoniae (pink), with the most divergent regions colored orange.

of residues (Figure 5). Based on the reaction mechanism of alanine racemases proposed elsewhere [29-31,50], $\mathrm{Alr}_{\mathrm{SP}}$ operates by a two-base mechanism where the $\alpha$ hydrogen of either D-alanine or L-alanine is abstracted and added by a different catalytic residue. Therefore, in the $\mathrm{D}$ - to L- direction, the reaction occurs with D-alanine binding to produce an external aldmine between PLP and D-alanine. Lys40 then abstracts the $\alpha$-hydrogen to produce a carbanonic quinonoid intermediate. Next, Tyr263' adds a proton to the $\mathrm{C} \alpha$ of the intermediate from the opposite side to produce an external aldimine between PLP and what is now L-alanine. Subsequent transaldimination liberates L-alanine and regenerates the LLP form of the enzyme.

Table 2 Average r.m.s. differences (Å) between the $\mathrm{C} \alpha$ atoms of $\mathrm{Alr}_{\mathrm{SP}}$ and alanine racemase structures from other Gram-positive bacteria

\begin{tabular}{llllll}
\hline & $\begin{array}{c}\text { PDB } \\
\text { ID }\end{array}$ & $\begin{array}{c}\text { Whole } \\
\text { monomer }\end{array}$ & $\begin{array}{l}\text { N- } \\
\text { terminus }\end{array}$ & $\begin{array}{l}\text { C- } \\
\text { terminus }\end{array}$ & $\begin{array}{l}\text { Active } \\
\text { site }\end{array}$ \\
\hline $\mathrm{Alr}_{\mathrm{GS}}$ & $1 \mathrm{SFT}$ & $1.23(46 \%)$ & $1.30(41 \%)$ & $0.57(56 \%)$ & $0.36(66 \%)$ \\
\hline $\mathrm{Alr}_{\mathrm{SL}}$ & $1 \mathrm{VFH}$ & $1.57(38 \%)$ & $1.92(34 \%)$ & $1.24(41 \%)$ & $0.67(46 \%)$ \\
\hline $\mathrm{Alr}_{\mathrm{BA}}$ & $3 \mathrm{HA} 1$ & $1.29(45 \%)$ & $1.59(41 \%)$ & $0.49(53 \%)$ & $0.38(65 \%)$ \\
\hline $\mathrm{Alr}_{\mathrm{EF}}$ & $3 \mathrm{E} 5 \mathrm{P}$ & $1.16(53 \%)$ & $1.48(52 \%)$ & $0.54(56 \%)$ & $0.46(71 \%)$ \\
\hline
\end{tabular}

Numbers in parenthesis denote sequence identity with AlrSP, (\%sequence identity $=$ Nidentity/Naligned).
In the LLP moiety, the C4" atom of the PLP cofactor is linked to the NZ of Lys40 by a double bond in the trans-configuration, forming an internal aldimine as in other alanine racemase structures [29,31-33]. The PLP cofactor is further stabilized by hydrogen bonds with the side chains of six residues (Tyr44, Arg136, His165, Ser203, Arg218 and Tyr352) and main chains of three residues (Ser203, Gly220, Asp221; Figure 4A). The hydrogen-bonded network also includes residues His199 and Tyr263", and was first described in $\mathrm{Alr}_{\mathrm{GS}}$ [29]. All of these residues are strictly conserved across the Grampositive structures, except for Asp221, which is replaced by an Ile in $\mathrm{Alr}_{\mathrm{BA}}$ and $\mathrm{Alr}_{\mathrm{GS}}$, a Val in $\mathrm{Alr}_{\mathrm{EF}}$, and a Leu in $\mathrm{Alr}_{\mathrm{SL}}[29,33]$.

We observed electron density consistent with a carbamylated lysine at the NZ terminus of Lys129, as seen in most other alanine racemase structures. Lys129 refined well as a carbamylated residue in this structure and is hydrogen bonded to the neighboring arginine residue. Shaw et al. [29] noted that this lysine residue is highly conserved, and later studies suggested that it helps to position the nearby arginine residue (Arg136 in $\mathrm{Alr}_{\mathrm{SP}}$ ) which interacts with the substrate's carboxylate group through hydrogen-bonding [28,32]. Arg136 is further positioned in $\mathrm{Alr}_{\mathrm{SP}}$ by a hydrogen bond to Ser309. Sequences of alanine racemases that contain a lysine in position 129 almost always have an accompanying serine or cysteine residue in the equivalent of position 309 [36]. Recently, the $\mathrm{Alr}_{\mathrm{BA}}$ structure was found to contain an aspargine residue bound to a chloride ion at the equivalent position of Lys129, which appears to play the same role as the carbamylated Lys of positioning the active site arginine [36]. An alignment of alanine racemase sequences by Couñago et al. revealed that the presence of an aspargine residue can occur at the equivalent position of Lys129 in $\mathrm{Alr}_{\mathrm{SP}}$ and is likely to be indicative of an internal chloride within the active site in the place of a carbamylated lysine. Notably this change from Lys to Ser appears to always be accompanied by a threonine at the equivalent position of Ser309, even though the threonine does not directly interact with the chloride ion.

The environments on either side of the pyridine ring of PLP are quite different, as reported previously for $\mathrm{Alr}_{\mathrm{GS}}[29,33]$. The side of the PLP that faces the dimer interface is polar in character, with many hydrophilic amino acid residues (including carbamylated Lys129, Arg136, His165 and Arg218), several water molecules and the hydrogen-bond network. The nonpolar side of PLP, in contact with the $\alpha / \beta$ barrel, contains several hydrophobic residues (Val38, Leu83, Leu85 and Phe163), no charged residues and no water molecules.

As observed in several other alanine racemase structures $[29,32,34,36]$, we identified extra density in the 
Table 3 Residues used in r.m.s. calculations

\begin{tabular}{|c|c|c|c|c|c|c|}
\hline & & $\mathrm{Alr}_{\mathrm{EF}}$ & Alr $_{\mathrm{SP}}$ & $\mathrm{Alr}_{\mathrm{GS}}$ & $\mathrm{Alr}_{\mathrm{BA}}$ & $\mathrm{Alr}_{\mathrm{SL}}$ \\
\hline $\mathrm{N}$-terminus & monomer $\mathrm{A}$ & $2-243$ & $1-239$ & $2-241$ & 4-245 & $3-246$ \\
\hline C-terminus & monomer $\mathrm{A}$ & $244-371$ & $240-367$ & $242-388$ & 246-389 & $247-378$ \\
\hline \multirow[t]{11}{*}{ Active site } & monomer $\mathrm{A}$ & $38-44$ & $38-44$ & $37-43$ & $39-45$ & $36-42$ \\
\hline & & $62-66$ & $61-65$ & $61-65$ & $63-67$ & $60-64$ \\
\hline & & $83-87$ & $82-86$ & $82-86$ & $84-88$ & $81-85$ \\
\hline & & 100-104 & 101-105 & 101-105 & 103-107 & 100-104 \\
\hline & & $\underline{128-141}$ & 125-138 & 125-138 & $127-140$ & 125-138 \\
\hline & & 164-172 & 160-168 & 161-169 & 163-171 & 163-171 \\
\hline & & 201-208 & 197-204 & 198-205 & 203-210 & 203-210 \\
\hline & & 219-226 & 215-222 & 216-223 & $221-228$ & $221-228$ \\
\hline & & $353-360$ & 349-356 & $351-358$ & 356-363 & 358-365 \\
\hline & monomer $B$ & $265-268$ & $261-264$ & 263-266 & $268-271$ & $268-271$ \\
\hline & & $311-316$ & $307-312$ & $309-314$ & $314-319$ & $315-320$ \\
\hline
\end{tabular}

active site of Alr ${ }_{\mathrm{SP}}$ adjacent to the PLP cofactor (Figure 4C). The position of this density corresponds to that of the acetate modeled in $\mathrm{Alr}_{\mathrm{GS}}$. In other structures, this location has been reported to contain propionate, alanine phosphonate, and a putative substrate molecule in $\operatorname{DadX}_{\text {PA }}[28-30,38]$. Water molecules in the same location are found in the $\mathrm{Alr}_{\mathrm{MT}}$ and $\mathrm{Alr}_{\mathrm{SL}}$ structures. After unsuccessfully attempting to model a variety of small molecules into the extra density, including acetate, we left this region of the model empty.

\section{Active site entryway}

The entryway to the active site in $\mathrm{Alr}_{\mathrm{SP}}$ comprises the $\alpha / \beta$ barrel domain of one monomer and residues from the C-terminal domain of the other monomer, and is about $13 \AA$ from the active site C4" atom of PLP. The entryway has a funnel-like shape, with its widest end towards the outside of the enzyme, narrowing as it approaches the PLP. The highly conserved residues comprising the entryway are distributed in layers beginning at the PLP site (Figures 6A and 6B): charged near the entrance, and mainly hydrophobic near the active site $[33,34]$. Mutagenesis has shown that these hydrophobic residues have an important role in controlling the substrate specificity of alanine racemase [51]. In $\mathrm{Alr}_{\mathrm{SP}}$, the inner layer is made up of residues Tyr263', Tyr352, Tyr282', and Ala169. Residues Arg307', Ile350, Arg288', and Asp170 make up the middle layer. The residues composing the middle and the inner layers are strictly conserved between $\mathrm{Alr}_{\mathrm{SP}}, \mathrm{Alr}_{\mathrm{EF}}, \mathrm{Alr}_{\mathrm{BA}}, \mathrm{Alr}_{\mathrm{GS}}$, and $\mathrm{Alr}_{\mathrm{SL}}$. An outer layer exists comprised of $\mathrm{Thr} 345$, Glu171, Val232 and Gly264', but these residues, which are able to interact with solvent directly, are not well conserved.

The $\mathrm{Alr}_{\mathrm{SP}}$ active site entryway includes the conserved pair of acidic residues Asp170 and Glu171. The equivalent residues in E. coli, Asp164 and Glu165, have been posited to play a role in substrate orientation [37]. Although the active sites of alanine racemases in general are moderate in size, it is difficult for inhibitors to access because of a constriction in the entryway corridor [34]. The smallest constriction in the entryway corridor of $\mathrm{Alr}_{\mathrm{SP}}$ is between Tyr263' and Tyr352 of the inner layer (Figure 6A), which provide an opening width of

Table 4 Kinetic parameters for the racemization of L- to D- and D- to L-alanine by alanine racemases from Grampositive bacteria

\begin{tabular}{|c|c|c|c|c|c|c|}
\hline \multirow[b]{2}{*}{ Enzyme [ref] } & \multicolumn{3}{|c|}{ D to $L$ direction } & \multicolumn{3}{|c|}{$L$ to $D$ direction } \\
\hline & $\mathrm{K}_{m}(\mathrm{mM})$ & $\mathrm{V}_{\max }(\mathrm{U} / \mathrm{mg})^{\mathrm{a}}$ & $\mathrm{k}_{\text {cat }}\left(\mathrm{min}^{-1}\right)$ & $\mathrm{K}_{m}(\mathrm{mM})$ & $\mathrm{V}_{\max }(\mathrm{U} / \mathrm{mg})^{\mathrm{a}}$ & $\mathbf{k}_{\text {cat }}\left(\min ^{-1}\right)$ \\
\hline Alr $_{\text {SP }}[21]$ & $2.1^{b}$ & $87.0^{\mathrm{b}}$ & NR & $1.9^{\mathrm{b}}$ & $84.8^{\mathrm{b}}$ & $N R$ \\
\hline Alr $_{\mathrm{GS}}$ [76] & $2.7^{c}$ & $1400^{c}$ & $\mathrm{NR}$ & $4.3^{c}$ & $2550^{c}$ & $N R$ \\
\hline Alr $_{\text {SL }}$ [77] & $0.4^{c}$ & NR & $3800^{c}$ & $0.4^{c}$ & NR & $3300^{c}$ \\
\hline $\mathrm{Alr}_{\mathrm{BA}}[36]$ & $2.8^{b}$ & $101^{\mathrm{b}}$ & NR & NR & NR & NR \\
\hline $\operatorname{Alr}_{\text {EF }}[78]$ & $2.2^{c}$ & $1210^{c}$ & $\sim 2340^{c}$ & $7.8^{c}$ & $3570^{c}$ & $\sim 2340^{c}$ \\
\hline
\end{tabular}

${ }^{\mathrm{a} O n e}$ unit is defined as the amount of enzyme that catalyzes racemization of $1 \mu \mathrm{mol}$ of substrate per minute.

${ }^{\mathrm{b}}$ At $23^{\circ} \mathrm{C}$. ${ }^{\mathrm{C}}$ At $37^{\circ} \mathrm{C}$. NR: not reported. 
only about $2.6 \AA$ for an active site inhibitor to pass through (the distance between the closest atoms of these two side chains with the van der Waals radius for each atom subtracted). As a result, the substrate entryway itself has been proposed as an alternative target for inhibitor development [32,34]. Wang et al. [52] have proposed this idea previously for another enzyme, histone deacetylase-like protein.

\section{Dimer interface}

Dimerization is essential for the catalytic activity of alanine racemase [47]. Both monomers contribute to the overall composition of the active site, the alanine entryway, and the binding pocket. Within the $\mathrm{Alr}_{\mathrm{SP}}$ dimer interface there are 33 hydrogen bonds and 10 salt bridges (Table 5). There are no disulfide or covalent bonds across the interface. 91 residues from each monomer are involved in intermonomer interactions. The buried surface areas of the A and B monomers are 3035 and 3020 $\AA^{2}$, respectively; both values are $19 \%$ of the total surface area of each monomer. The interface surface area is similar to that seen in the closely related $\mathrm{Alr}_{\mathrm{EF}}$ and $\mathrm{Alr}_{\mathrm{GS}}$ (Table 5). 30\% of the interface residues in $\mathrm{Alr}_{\mathrm{SP}}$ are polar, $47 \%$ are non-polar, and $22 \%$ are charged.

Disruption of the dimer interface could be used to inhibit alanine racemase activity, and has been successfully used on drug targets in HIV and HCV [53-55], and on caspases [56]. Inspection of the residues that participate in the dimer interface of $\mathrm{Alr}_{\mathrm{SP}}$ on a structure-based sequence alignment (Figure 2) makes it apparent that that many of these residues are highly conserved, and also participate in substrate guidance (such as middle and inner entryway residues Tyr282', Tyr352, Arg307', Ile350, Arg288', Asp170) or catalysis (e.g. Lys40, Tyr263').

\section{Pentagonal water molecules in the active site}

A cluster of hydrogen-bonded water molecules forms an ordered pentagonal ring and some adjacent partial rings in the active site entryways of both monomers of $\mathrm{Alr}_{\mathrm{SP}}$ (Figure 7). The pentagonal ring waters are located adjacent to the substrate binding site and between residues Tyr263" and Tyr282". They are positioned at the interface of monomer A and B and appear to be involved in the dimer interface, making direct or indirect hydrogen bonds with interface residues (Asp170, Tyr263', Tyr282', Tyr288', Arg307', Tyr352). The distance between the water oxygen atoms that form each side of the pentagon is about $2.7 \AA$. The pentagonal ring is hydrogen-bonded directly to the protein at five atoms (Tyr282' OH, Arg307' NH1, and Arg288' NH2 and NE from the entryway inner and middle layers, and Val308' O) and makes hydrogen bonds with other waters both deeper in the active site and at the outer region of the entryway. 

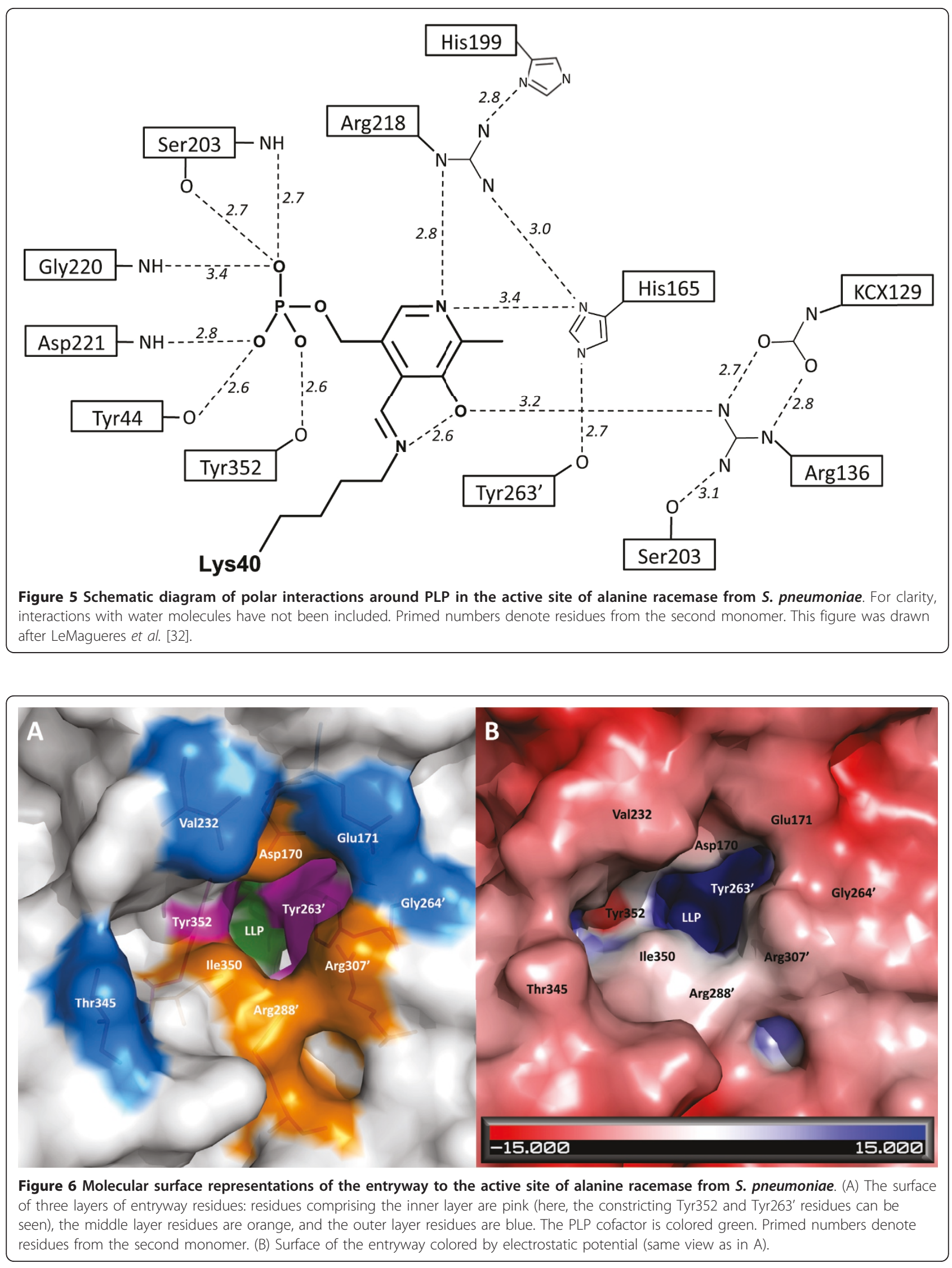
Table 5 Intermonomer interactions for alanine racemases from Gram-positive bacteria calculated using PISA [69] and PROTORP [70]

\begin{tabular}{|c|c|c|c|c|c|c|c|c|c|}
\hline & \multicolumn{2}{|c|}{ Buried surface area $\left(\AA^{2}\right)$} & \multirow[t]{2}{*}{ H-bonds } & \multirow[t]{2}{*}{ Salt link } & \multicolumn{2}{|c|}{ \# residues } & \multicolumn{3}{|c|}{$\%$ interface residues } \\
\hline & Monomer A & Monomer B & & & $A$ & B & polar & non-polar & charged \\
\hline $\operatorname{Alr}_{\mathrm{SP}}$ & 3035 & 3020 & 33 & 10 & 91 & 91 & 30 & 47 & 22 \\
\hline $\operatorname{Alr}_{\mathrm{GS}}$ & 3058 & 3109 & 43 & 17 & 89 & 88 & 27 & 43 & 30 \\
\hline $\mathrm{Alr}_{\mathrm{SL}}$ & 2800 & 2799 & 26 & 6 & 87 & 87 & 39 & 43 & 18 \\
\hline $\mathrm{Alr}_{\mathrm{BA}}$ & 3529 & 3529 & 45 & 10 & 93 & 95 & 28 & 44 & 27 \\
\hline$\overline{\mathrm{Alr}_{\mathrm{EF}}}$ & 2936 & 2936 & 38 & 12 & 86 & 86 & 32 & 41 & 28 \\
\hline
\end{tabular}

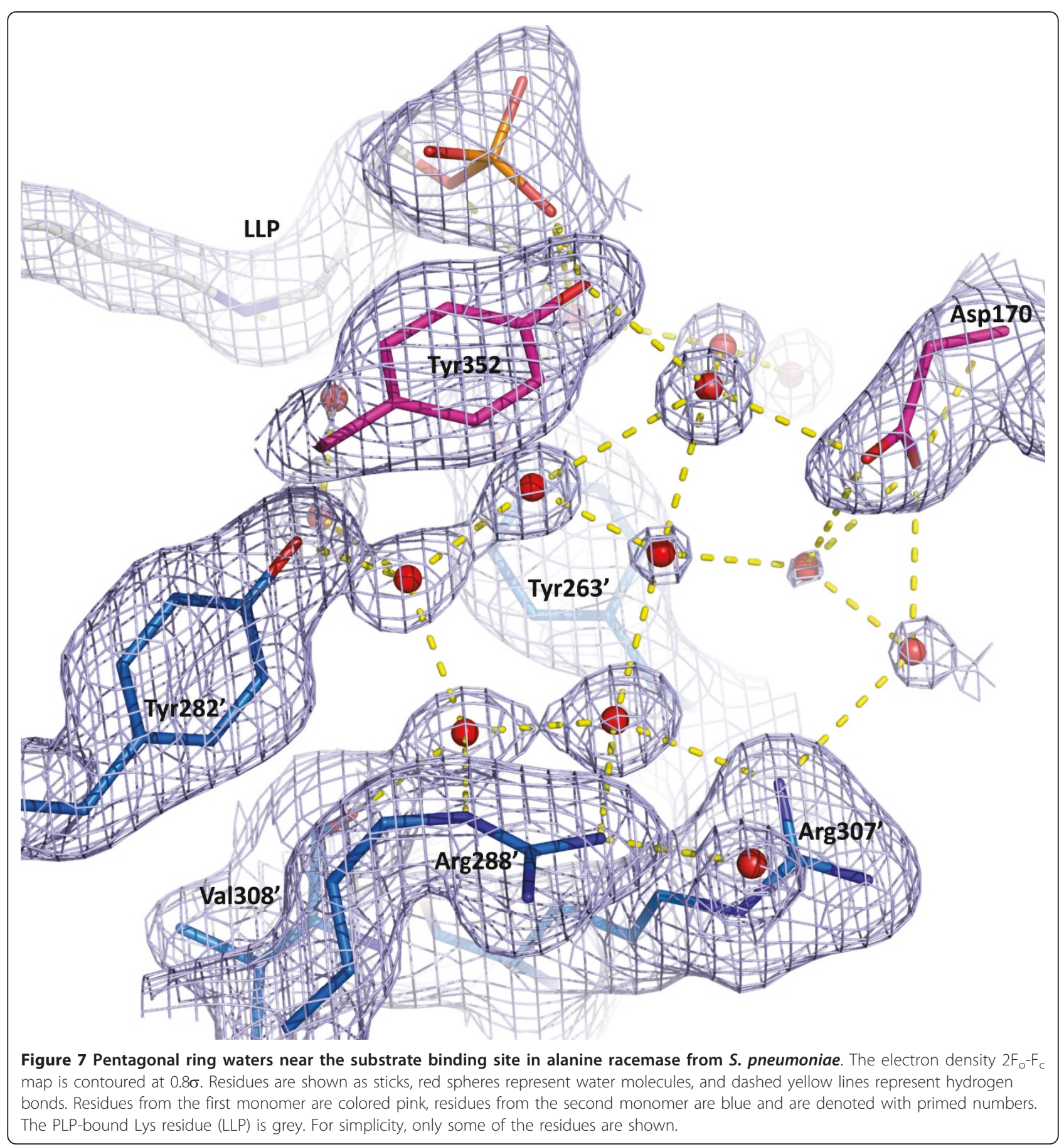


The hydrogen bond network we have identified could be facilitating substrate movement or proton transfer into the active site. Analysis of conserved water sites in $\mathrm{Alr}_{\mathrm{GS}}$ has been reported previously and the authors postulated that these sites could be involved in proton transfer or solvent shift into the active site [57]. In the high resolution structure of the protein crambin, Teeter reported pentagonal rings of water molecules which were felt to have a role in stabilizing protein structure or in catalysis [58]. Pentagonal ring waters have not yet been reported for other alanine racemases, but depending on which monomer is observed, the $\mathrm{Alr}_{\mathrm{BA}}$ and $\mathrm{Alr}_{\mathrm{GS}}$ structures have 3 to 4 of the 5 pentagonal waters present in $\mathrm{Alr}_{\mathrm{SP}}$, the $\mathrm{Alr}_{\mathrm{SL}}$ structure has 2 of the 5 pentagonal waters, and the $\mathrm{Alr}_{\mathrm{EF}}$ structure does not have any pentagonal ring waters, although this could be due to limits in structural resolution.

\section{Alanine racemase as a target for drug design}

In this section we review some of the challenges encountered in developing inhibitors for alanine racemases as a family and we explain the contribution of the $S$. pneumoniae structure to this process. Finally we offer our assessment of the most useful approaches to alanine racemase inhibitor development.

Challenges involved in designing inhibitors for alanine racemase are easy to identify. To begin with, there have been few reports to date of alanine racemase inhibitors with any true specificity. Incorporating features of the active site in drug design has been challenging because the structure of the active site is thought to have limited accessibility. Further, several inhibitors have been found to cross react with human enzymes that contain PLP. Even so, our analysis of alanine racemase structures has allowed us to identify key features that could be incorporated into the inhibitor development process. Since these key features are also present in the S. pneumoniae enzyme structure, it confirms that these features are not artifacts or incidental findings but conserved features that can be targeted in the development of a class of inhibitors specific to bacterial alanine racemases. Therefore the structure of the $S$. pneumoniae enzyme is valuable to racemase drug design efforts.

In addition, one new feature relevant to the traditional drug design approach of blocking the active site that we report here for $\mathrm{Alr}_{\mathrm{SP}}$ is the pentagonal water network within the active site. Several of these waters are conserved in other alanine racemase species. That being the case, the conserved waters could be incorporated within an in silico pharmacophore as a polar site capable of receiving or donating a hydrogen bond depending on its protonation state. Unfortunately, to date testing of compounds identified from in silico screening has not resulted in the identification of strong inhibitors.
The earliest drug development work on alanine racemase was carried out in the absence of a crystal structure and resulted in the development of a cycloserine, a small, covalent inhibitor of alanine racemase and other PLP-containing enzymes [59] that lacks any specific interactions with elements in the active site. More recent in silico drug design work carried out using the structure of alanine racemase has defined a pharmacophore situated within the active site near the alanine racemase acetate binding site, a site reported consistently within alanine racemase structures [60]. However, analysis of the narrow entryway to the active site PLP suggests that access to the proposed interior binding pockets of the enzyme is likely to be limited, especially for larger compounds [32,34]. To be an effective drug target it is important the active site be accessible, therefore standard structure-aided inhibitor design approaches are limited for alanine racemase.

Since, as illustrated by the $\mathrm{Alr}_{\mathrm{SP}}$ structure, entryway to the interior binding pocket of alanine racemase is very tight, the drug design problem for alanine racemase resembles a "ship in a bottle" (SIAB) dilemma. Once inside the interior pocket, the compounds proposed to bind to the active site would fit well but these compounds may only make it to the interior with difficulty $[32,34,36]$. This view is of course an oversimplification, as the entryway is likely to 'breathe' and adjust, and there is a monomer-dimer equilibrium for alanine racemase that would affect the geometry and accessibility of internal active site cavities. However, the restricted access and size of the alanine racemase active site is one reason it has not been targeted by major pharmaceutical companies in the recent past (Bussiere, Dirk; personal communication).

If a drug design project involving an enzyme with a SIAB active site is to be successful, there are four obvious approaches to inhibitor development: high throughput screening (HTS), blocking the opening, interfering with active site assembly, or developing drugs that enter in one shape and adopt a new conformation after binding, thus trapping them in the active site.

HTS would bypass any of the complexities associated with active site access and would provide a set of compounds that inhibit the enzyme by any and all means, to be deconvoluted later. Given that the active site features we describe for the $S$. pneumoniae enzyme are highly conserved in the bacterial structures reported to date, the alanine racemase inhibitors identified by HTS would likely be broad-spectrum in their action. But a broad spectrum of activity should not be viewed in a negative light, as almost all major classes of antibiotics developed to date are broad spectrum. This includes beta-lactams like penicillin and cephalosporins, fluoroquinolones, 
tetracyclines, even macrolides. In fact the only specificity among anti-bacterial classes currently in use would be that some target preferentially Gram-positives, Gramnegatives, mycobacteria or anaerobes.

Blocking the opening would involve the design of compounds that interact with residues in the entryway and that extend toward the PLP moiety, but that might not reach the interior binding pocket. In our previous work on the alanine racemase from $P$. aeruginosa, $M$. tuberculosis and B. anthracis, we described a highly conserved and layered entryway to the active site that contains both hydrophobic and polar features. The hydrophobic regions are bound by three tyrosines and an alanine in the inner layer of entryway, while the polar areas include two arginines and one aspartate located in the middle layer. These highly conserved features are present in the S. pneumoniae structure and all alanine racemase structures reported to date. An entryway of this type has not been described in human PLP-containing enzymes. For example, human serine racemase, which like alanine racemase reacts with D-cycloserine, belongs to the Fold type II family of PLPcontaining enzymes and would be not be expected to cross-react with any specific alanine racemase inhibitors [61]. The alanine racemase topology is termed Fold type III and is unique among PLP-containing enzymes. It seems likely, therefore, that designing inhibitors that interact with conserved motifs found in the entryway could represent a potential source of specificity in the drug design process.

Interfering with active site assembly would, in the case of alanine racemase, require compounds that inhibit dimer formation, none of which have been reported for alanine racemase to date. However, dimer inhibitors have been reported in other systems such as HIV protease [53-55]. Finally, a compound that could enter the active site of alanine racemase then undergo a conformational switch rendering the enzyme inactive would make an effective inhibitor, but this type of inhibitor has not yet been reported for this class of enzyme.

\section{Conclusions}

Alanine racemase is a promising target for antibacterial drugs because it is both essential in bacteria and absent in humans. We report the high-resolution crystal structure of alanine racemase from S. pneumoniae. Overall, the structure shares the conserved active site and topology found across all alanine racemases. Known alanine racemase inhibitors such as D-cycloserine, alanine phosphonate, and other substrate analogues are not specific, acting on other PLP-containing enzymes such as transaminases, also found in humans $[59,62]$. In order to be clinically relevant, new inhibitors of alanine racemase with more specificity need to be developed. This structure is an essential starting point for the design of more specific inhibitors of alanine racemase in $S$. pneumoniae. Our investigations have identified three potential areas in the $\mathrm{Alr}_{\mathrm{SP}}$ structure that could be targeted in a structure-based inhibitor design: the active site, the residues forming the dimer interface, and the active site entryway in particular, since designing a 'plug' to fit the funnel shape of this feature is intuitively attractive.

\section{Methods}

\section{Protein expression, purification and crystallization}

The expression, purification and crystallization of $\mathrm{Alr}_{\mathrm{SP}}$ have been described previously [21]. Briefly, the gene encoding $\mathrm{Alr}_{\mathrm{SP}}$ was cloned into pET17 (Novagen) and the resulting vector transformed into E. coli BL21 (DE3) pLysS cells (Novagen). Overexpression of $\mathrm{Alr}_{\mathrm{SP}}$ was induced in a culture of these cells, which were then lysed to extract the protein. The recombinant $\mathrm{Alr}_{\mathrm{SP}}$ was purified using ammonium sulfate precipitation, anionexchange chromatography, hydrophobic interaction chromatography, and finally, size-exclusion chromatography. Crystals of $\mathrm{Alr}_{\mathrm{SP}}$ were grown at $4^{\circ} \mathrm{C}$ in $1.2 \mathrm{M}$ Na Citrate, 0.1 M MES, pH 7.2, and 10\% glycerol (protein concentration $23 \mathrm{mg} / \mathrm{ml}$, drop size $4 \mu \mathrm{l}+4 \mu \mathrm{l}$ ) using the sitting drop vapor diffusion method, then flash-frozen in liquid $\mathrm{N}_{2}$ for data collection. No additional cryoprotectant was required.

\section{Data collection and processing}

Diffraction data were collected to $2.0 \AA$ resolution at $100 \mathrm{~K}$ using a Rigaku FR-E generator and an HTC detector at $45 \mathrm{kV}$ and $45 \mathrm{~mA}$ with $\mathrm{Cu} \mathrm{K} \alpha$ radiation at Rigaku MSC (The Woodlands, TX). The crystals belonged to the space group $\mathrm{P} 3_{1} 21$ with the unit cell parameters $\mathrm{a}=\mathrm{b}=119.97 \AA, \mathrm{c}=118.10 \AA, \alpha=\beta=90^{\circ}$ and $\gamma=120^{\circ}$. The data were processed and merged using the HKL package version 1.96.6 [63]. Data collection and processing statistics are listed in Table 1.

\section{Structure determination and refinement}

The structure of Alr $r_{S P}$ was solved by molecular replacement using CNS version 1.1 [42]. Alr GS $_{\text {(PDB ID 1SFT) }}$ [29] without the PLP cofactor was used as a search model, and two monomers per asymmetric unit were assumed, as suggested by a Matthews coefficient [64] of 3.0 with a solvent content of $59.0 \%$. Cross-rotation and translation searches were completed and the best solution was used as an initial model for model building. After rigid body refinement in CNS, ARP/wARP version 6.1 [65] was used to trace the initial protein model and build side chains. Further refinement was carried out using simulated annealing and conjugation gradient minimization. When $97 \%$ of residues were built, the cofactor PLP and the carbamylated lysine were placed, and 
positional and B-factor refinements were continued resulting in an $R$ and $R_{\text {free }}$ of 31.9 and $33.9 \%$, respectively. Water molecules were added using the waterpicking script in CNS, and further cycles of positional and $B_{\text {iso }}$ refinements brought the $R$ and $R_{\text {free }}$ to 20.7 and $25.7 \%$, respectively. Since previous alanine racemase structures have shown indications of subdomain movement, we tried TLS refinement [43]. We used the TLS motion determination server $[66,67]$ to produce modified PDB files and TLS input files for the structure partitioned into either one, five or twenty TLS groups, then further refined these models in Refmac5 version 5.5.0109 [44]. All models resulted in similar improvements in $\mathrm{R}$ and $R_{\text {free }}$ so we used the simplest option, which treated all protein atoms found in the asymmetric unit as a single rigid body (one TLS group). PLP and Lys40 were replaced with an LLP residue (PLP covalently bound to lysine), and TLS refinement was completed using Refmac5. The final model has an $\mathrm{R}$ and $\mathrm{R}_{\text {free }}$ of 16.8 and $20.0 \%$, respectively. Refinement statistics are listed in Table 1. Structure factors and final atomic coordinates for AlrSP have been deposited in the Protein Databank (PDB ID: 3S46). B-factor values and correlation coefficients were calculated using the programs Baverage and Overlapmap from the CCP4 suite [44].

\section{Structural and sequence comparisons}

The multiple structure-based sequence alignment and structural superpositions of $\mathrm{Alr}_{\mathrm{SP}}$ with closely related structures were performed using the protein structure comparison service (SSM) at the European Bioinformatics Institute (http://www.ebi.ac.uk/msd-srv/ssm) [68]. The PDB IDs of the structures used were: 1SFT $\left(\mathrm{Alr}_{\mathrm{GS}}\right)$, 1VFH $\left(\mathrm{Alr}_{\mathrm{SL}}\right)$, 3HA1 $\left(\mathrm{Alr}_{\mathrm{BA}}\right)$, and 3E5P $\left(\mathrm{Alr}_{\mathrm{EF}}\right)$. Table 3 lists the residues from these structures used in the superpositions. Intermonomer interactions were analysed using the Protein Interfaces, Surfaces and Assemblies service (PISA) at the European Bioinformatics Institute (http://www.ebi.ac.uk/msd-srv/prot_int/pistart. html) [69], and the Protein-Protein interface analysis server (PROTORP) Server (http://www.bioinformatics. sussex.ac.uk/protorp/ index.html) [70].

\section{Figure preparation}

Representations of molecules were prepared using the programs PyMOL [71] and BKChem (http://bkchem.zirael.org/index.html). The sequence alignment was visualized using Jalview [72]. The electrostatic potential of the $\mathrm{Alr}_{\mathrm{SP}}$ surface was calculated using the Adaptive Poisson-Boltzmann Solver (APBS) [73] through PyMOL. Default configurations were used for calculations. PQR files for use with APBS were generated using the PDB 2PQR Server (http://kryptonite.nbcr.net/pdb2pqr/) [74] and the Dundee PRODRG2 Server (http://davapc1. bioch.dundee.ac.uk/prodrg/) [75].

\section{Acknowledgements}

We wish to thank Eileen Murphy for her expert technical assistance, Pierre LeMagueres, Mitchell Miller, John J. Tanner and Sergey Lindeman for their expert crystallographic guidance, Michael J. Benedik and James M. Briggs for their helpful discussion and inspiration, and MSC Rigaku, especially Kris Tesh, for data collection assistance. Funding from the National Institutes of Health, the University of Otago, and the Robert A. Welch Foundation supported this work.

\section{Author details}

'Research Institute of Pharmaceutical Sciences, College of Pharmacy, Seoul National University, Seoul, Korea. ${ }^{2}$ Department of Biochemistry, University of Otago, Dunedin, New Zealand. ${ }^{3}$ Department of Biology and Biochemistry, University of Houston, Houston, TX, USA. ${ }^{4}$ Department of Biochemistry and Cell Biology, Rice University, Houston, TX, USA.

\section{Authors' contributions}

HI performed research, helped draft the manuscript, analyzed results and prepared figures. MS helped to refine the structure and draft the manuscript, analyzed results and prepared figures. US and MD performed research and critically appraised the manuscript. KK designed research, supervised the work, organized financial support, and critically appraised the manuscript. All authors read and approved the final manuscript.

Received: 11 October 2010 Accepted: 25 May 2011

Published: 25 May 2011

\section{References}

1. Osler SW: Medicine in the Nineteenth Century. Aequanimitas: with other addresses to medical students, nurses and and practitioners of medicine Philadelphia: P. Blakiston's Son \& Co; 1905, 217-262.

2. Jedrzejas MJ: Pneumococcal virulence factors: structure and function. Microbiol Mol Biol Rev 2001, 65:187-207.

3. Hale KA, Isaacs D: Antibiotics in childhood pneumonia. Paediatr Respir Rev 2006, 7:145-151.

4. World Health Organization Initiative for Vaccine Research: Acute Respiratory Infections (Update September 2009).[http://www.who.int/ vaccine_research/diseases/ari/en/].

5. O'Brien KL, Wolfson L, Watt JP, Henkle E, Deloria-Knoll M, MCCall N, Lee E, Mulholland K, Levine OS, Cherian T: Burden of disease caused by Streptococcus pneumoniae in children younger than 5 years: global estimates. Lancet 2009, 374:893-902.

6. Bartlett JG, Froggatt JW: Antibiotic resistance. Arch Otolaryngol Head Neck Surg 1995, 121:392-396.

7. File TM: Community-acquired pneumonia. Lancet 2003, 362:1991-2001.

8. Brundage JF: Interactions between influenza and bacterial respiratory pathogens: implications for pandemic preparedness. Lancet Infect Dis 2006, 6:303-312

9. Klugman KP, Madhi SA: Pneumococcal vaccines and flu preparedness. Science 2007, 316:49-50.

10. Palacios G, Hornig M, Cisterna D, Savji N, Bussetti AV, Kapoor V, Hui J, Tokarz R, Briese T, Baumeister E, Lipkin Wl: Streptococcus pneumoniae coinfection is correlated with the severity of $\mathrm{H} 1 \mathrm{~N} 1$ pandemic influenza. PLOS ONE 2009, 4:e8540.

11. Krause KL, Stager C, Gentry LO: Prevalence of penicillin-resistant pneumococci in Houston, Texas. Am J Clin Pathol 1982, 77:210-213.

12. Lynch JP, Zhanel GG: Streptococcus pneumoniae: does antimicrobial resistance matter? Semin Respir Crit Care Med 2009, 30:210-238

13. Watson DA, Musher DM, Jacobson JW, Verhoef J: A brief history of the pneumococcus in biomedical research: a panoply of scientific discovery. Clin Infect Dis 1993, 17:913-924.

14. File TM Jr: Clinical implications and treatment of multiresistant Streptococcus pneumoniae pneumonia. Clin Microbiol Infect 2006, 12(Suppl 3):31-41.

15. Jacobs MR, Felmingham D, Appelbaum PC, Gruneberg RN: The Alexander Project 1998-2000: susceptibility of pathogens isolated from 
community-acquired respiratory tract infection to commonly used antimicrobial agents. J Antimicrob Chemother 2003, 52:229-246.

16. Reinert RR: The antimicrobial resistance profile of Streptococcus pneumoniae. Clin Microbiol Infect 2009, 15(Suppl 3):7-11.

17. Farrell DJ, Couturier C, Hryniewicz W: Distribution and antibacteria susceptibility of macrolide resistance genotypes in Streptococcus pneumoniae: PROTEKT Year 5 (2003-2004). Int J Antimicrob Agents 2008, 31:245-249.

18. Lambert MP, Neuhaus FC: Factors affecting the level of alanine racemase in Escherichia coli. J Bacteriol 1972, 109:1156-1161.

19. Milligan DL, Tran SL, Strych U, Cook GM, Krause KL: The alanine racemase of Mycobacterium smegmatis is essential for growth in the absence of D-alanine. J Bacteriol 2007, 189:8381-8386.

20. Chacon O, Feng Z, Harris NB, Caceres NE, Adams LG, Barletta RG: Mycobacterium smegmatis D-Alanine Racemase Mutants Are Not Dependent on D-Alanine for Growth. Antimicrob Agents Chemother 2002, 46:47-54.

21. Strych U, Davlieva M, Longtin J, Murphy E, Im H. Benedik M, Krause K. Purification and preliminary crystallization of alanine racemase from Streptococcus pneumoniae. BMC Microbiol 2007, 7:40.

22. Silverman RB: The potential use of mechanism-based enzyme inactivators in medicine. J Enzyme Inhib 1988, 2:73-90.

23. Veerapandian B: Three dimensional structure-aided drug design. In Burger's Medicinal Chemistry and Drug Discovery Volume 1.. 5 edition. Edited by: Wolff ME. New York: John Wiley 1995:303-348.

24. Marrone TJ, Briggs JM, McCammon JA: Structure-based drug design: computational advances. Annu Rev Pharmacol Toxicol 1997, 37:71-90.

25. Blundell TL: Structure-based drug design. Nature 1996, 384:23-26.

26. Fenn TD, Holyoak T, Stamper GF, Ringe D: Effect of a Y265F mutant on the transamination-based cycloserine inactivation of alanine racemase. Biochemistry 2005, 44:5317-5327.

27. Fenn TD, Stamper GF, Morollo AA, Ringe D: A side reaction of alanine racemase: transamination of cycloserine. Biochemistry 2003, 42:5775-5783.

28. Morollo AA, Petsko GA, Ringe D: Structure of a Michaelis complex analogue: propionate binds in the substrate carboxylate site of alanine racemase. Biochemistry 1999, 38:3293-3301.

29. Shaw JP, Petsko GA, Ringe D: Determination of the structure of alanine racemase from Bacillus stearothermophilus at 1.9-Å resolution. Biochemistry 1997, 36:1329-1342.

30. Stamper GF, Morollo AA, Ringe D: Reaction of alanine racemase with 1aminoethylphosphonic acid forms a stable external aldimine. Biochemistry 1998, 37:10438-10445.

31. Watanabe A, Yoshimura T, Mikami B, Hayashi H, Kagamiyama H, Esaki N: Reaction mechanism of alanine racemase from Bacillus stearothermophilus. J Biol Chem 2002, 277:19166-19172.

32. LeMagueres P, Im H, Dvorak A, Strych U, Benedik M, Krause KL: Crystal structure at $1.45 \AA$ resolution of alanine racemase from a pathogenic bacterium, Pseudomonas aeruginosa, contains both internal and external aldimine forms. Biochemistry 2003, 42:14752-14761.

33. Noda M, Matoba Y, Kumagai T, Sugiyama M: Structural evidence that alanine racemase from a D-cycloserine-producing microorganism exhibits resistance to its own product. J Biol Chem 2004, 279:46153-46161.

34. LeMagueres P, Im H, Ebalunode J, Strych U, Benedik MJ, Briggs JM, Kohn H, Krause KL: The $1.9 \AA$ crystal structure of alanine racemase from Mycobacterium tuberculosis contains a conserved entryway into the active site. Biochemistry 2005, 44:1471-1481.

35. Au K, Ren J, Walter TS, Harlos K, Nettleship JE, Owens RJ, Stuart DI, Esnouf RM: Structures of an alanine racemase from Bacillus anthracis (BA0252) in the presence and absence of (R)-1-aminoethylphosphonic acid (I-Ala-P). Acta Crystallogr Sect F Struct Biol Cryst Commun 2008, 64:327-333.

36. Couñago R, Davlieva M, Strych U, Hill R, Krause K: Biochemical and structural characterization of alanine racemase from Bacillus anthracis (Ames). BMC Struct Biol 2009, 9:53.

37. Wu D, Hu T, Zhang L, Chen J, Du J, Ding J, Jiang H, Shen X: Residues Asp164 and Glu165 at the substrate entryway function potently in substrate orientation of alanine racemase from E. coli: Enzymatic characterization with crystal structure analysis. Protein Sci 2008, 17:1066-1076

38. Priyadarshi A, Lee EH, Sung MW, Nam KH, Lee WH, Kim EE, Hwang KY: Structural insights into the alanine racemase from Enterococcus faecalis. Biochim Biophys Acta 2009, 1794:1030-1040.
39. Ondrechen MJ, Briggs JM, McCammon JA: A model for enzyme-substrate interaction in alanine racemase. J Am Chem Soc 2001, 123:2830-2834

40. Watanabe A, Yoshimura T, Mikami B, Esaki N: Tyrosine 265 of alanine racemase serves as a base abstracting alpha-hydrogen from L-alanine: the counterpart residue to lysine 39 specific to D-alanine. J Biochem 1999, 126:781-786.

41. Sun S, Toney MD: Evidence for a two-base mechanism involving tyrosine-265 from arginine-219 mutants of alanine racemase. Biochemistry 1999, 38:4058-4065.

42. Brunger AT, Adams PD, Clore GM, DeLano WL, Gros P, Grosse-Kunstleve RW Jiang JS, Kuszewski J, Nilges M, Pannu NS, et al: Crystallography \& NMR system: A new software suite for macromolecular structure determination. Acta Crystallogr D Biol Crystallogr 1998, 54:905-921.

43. Schomaker $\mathrm{V}$, Trueblood KN: On the rigid-body motion of molecules in crystals. Acta Crystallogr B 1968, 24:63-76.

44. Collaborative Computational Project Number 4: The CCP4 Suite: Programs for Protein Crystallography. Acta Crystallogr D Biol Crystallogr 1994, 50:760-763.

45. Laskowski RA, MacArthur MW, Moss DS, Thornton JM: PROCHECK: a program to check the stereochemical quality of protein structures. J Appl Crystallogr 1993, 26:283-291.

46. Kleywegt GJ, Jones TA: Databases in protein crystallography. Acta Crystallogr D Biol Crystallogr 1998, 54:1119-1131.

47. Strych U, Benedik MJ: Mutant analysis shows that alanine racemases from Pseudomonas aeruginosa and Escherichia coli are dimeric. J Bacteriol 2002, 184:4321-4325

48. Yokoigawa $K$, Okubo $Y$, Soda K: Subunit interaction of monomeric alanine racemases from four Shigella species in catalytic reaction. FEMS Microbiol Lett 2003, 221:263-267.

49. Ju J, Xu S, Furukawa Y, Zhang Y, Misono H, Minamino T, Namba K, Zhao B, Ohnishi K: Correlation between catalytic activity and monomer-dimer equilibrium of bacterial alanine racemases. J Biochem 2011, 149:83-89.

50. Spies MA, Woodward JJ, Watnik MR, Toney MD: Alanine racemase free energy profiles from global analyses of progress curves. J Am Chem Soc 2004, 126:7464-7475

51. Patrick WM, Weisner J, Blackburn JM: Site-directed mutagenesis of Tyr354 in Geobacillus stearothermophilus alanine racemase identifies a role in controlling substrate specificity and a possible role in the evolution of antibiotic resistance. Chembiochem 2002, 3:789-792.

52. Wang DF, Wiest $\mathrm{O}$, Helquist $\mathrm{P}$, Lan-Hargest HY, Wiech NL: On the function of the $14 \AA$ long internal cavity of histone deacetylase-like protein: implications for the design of histone deacetylase inhibitors. J Med Chem 2004, 47:3409-3417.

53. Boggetto N, Reboud-Ravaux M: Dimerization inhibitors of HIV-1 protease. Biol Chem 2002, 383:1321-1324

54. Song M, Rajesh S, Hayashi Y, Kiso Y: Design and synthesis of new inhibitors of HIV-1 protease dimerization with conformationally constrained templates. Bioorg Med Chem Lett 2001, 11:2465-2468

55. Strosberg AD: Breaking the spell: drug discovery based on modulating protein-protein interactions. Expert Rev Proteomics 2004, 1:141-143.

56. Scheer JM, Romanowski MJ, Wells JA: A common allosteric site and mechanism in caspases. Proc Natl Acad Sci USA 2006, 103:7595-7600.

57. Mustata G, Briggs JM: Cluster analysis of water molecules in alanine racemase and their putative structural role. Protein Eng Des Sel 2004 17:223-234.

58. Teeter MM: Water structure of a hydrophobic protein at atomic resolution: Pentagon rings of water molecules in crystals of crambin. Proc Natl Acad Sci USA 1984, 81:6014-6018.

59. Weinstein L: Antimicrobial agents: drugs used in the chemotherapy of tuberculosis and leprosy. In The pharmacological basis of therapeutics.. 5 edition. Edited by: Goodman LS,Gilman A. New York: Macmillan Publishing Co. Inc; 1975:1201-1223.

60. Mustata Gl, Briggs JM: A structure-based design approach for the identification of novel inhibitors: application to an alanine racemase. J Comput Aided Mol Des 2002, 16:935-953.

61. Smith MA, Mack V, Ebneth A, Moraes I, Felicetti B, Wood M, Schonfeld D, Mather O, Cesura A, Barker J: The structure of mammalian serine racemase: evidence for conformational changes upon inhibitor binding. J Biol Chem 2010, 285:12873-12881.

62. Walsh C: Antibiotics: Actions, origins, resistance Washington, DC: American Society for Microbiology Press; 2003. 
63. Otwinowski Z, Minor W: Processing of X-ray diffraction data collected in oscillation mode. Methods Enzymol 1997, 276:307-326.

64. Matthews BW: Solvent content of protein crystals. J Mol Biol 1968 33:491-497.

65. Lamzin VS, Wilson KS: Automated refinement for protein crystallography. Methods Enzymol 1997, 277:269-305.

66. Painter J, Merritt EA: Optimal description of a protein structure in terms of multiple groups undergoing TLS motion. Acta Crystallogr D Biol Crystallogr 2006, 62:439-450.

67. Painter J, Merritt EA: TLSMD web server for the generation of multi-group TLS models. J Appl Crystallogr 2006, 39:109-111.

68. Krissinel $E$, Henrick K: Secondary-structure matching (SSM), a new tool for fast protein structure alignment in three dimensions. Acta Crystallogr D Biol Crystallogr 2004, 60:2256-2268.

69. Krissinel $E$, Henrick K: Inference of macromolecular assemblies from crystalline state. J Mol Biol 2007, 372:774-797.

70. Reynolds C, Damerell D, Jones S: ProtorP: a protein-protein interaction analysis server. Bioinformatics 2009, 25:413-414.

71. DeLano WL: The PyMOL Molecular Graphics System.[http://www.pymol. org/].

72. Waterhouse AM, Procter JB, Martin DM, Clamp M, Barton GJ: Jalview Version 2-a multiple sequence alignment editor and analysis workbench. Bioinformatics 2009, 25:1189-1191.

73. Baker NA, Sept D, Joseph S, Holst MJ, McCammon JA: Electrostatics of nanosystems: application to microtubules and the ribosome. Proc Natl Acad Sci USA 2001, 98:10037-10041.

74. Dolinsky TJ, Nielsen JE, McCammon JA, Baker NA: PDB 2PQR: an automated pipeline for the setup of Poisson-Boltzmann electrostatics calculations. Nucleic Acids Res 2004, 32:W665-667.

75. Schuttelkopf AW, van Aalten DM: PRODRG: a tool for high-throughput crystallography of protein-ligand complexes. Acta Crystallogr D Biol Crystallogr 2004, 60:1355-1363.

76. Inagaki K, Tanizawa K, Badet B, Walsh CT, Tanaka H, Soda K: Thermostable alanine racemase from Bacillus stearothermophilus: molecular cloning of the gene, enzyme purification, and characterization. Biochemistry 1986, 25:3268-3274.

77. Noda M, Matoba $Y$, Kumagai T, Sugiyama M: A novel assay method for an amino acid racemase reaction based on circular dichroism. Biochem $J$ 2005, 389:491-496.

78. Badet B, Walsh C: Purification of an alanine racemase from Streptococcus faecalis and analysis of its inactivation by (1-aminoethyl)phosphonic acid enantiomers. Biochemistry 1985, 24:1333-1341.

doi:10.1186/1471-2180-11-116

Cite this article as: Im et al.: The crystal structure of alanine racemase from Streptococcus pneumoniae, a target for structure-based drug design. BMC Microbiology 2011 11:116.

\section{Submit your next manuscript to BioMed Central and take full advantage of:}

- Convenient online submission

- Thorough peer review

- No space constraints or color figure charges

- Immediate publication on acceptance

- Inclusion in PubMed, CAS, Scopus and Google Scholar

- Research which is freely available for redistribution

Submit your manuscript at www.biomedcentral.com/submit
C) Biomed Central 